\title{
In vitro Sensitivity to Fluconazole through Vitek II Systems, of Strains of Candida spp. In Patients with Oropharyngeal Candidiasis and HIV/AIDS
} Verónica Gaona-Flores*, Roberto Quiróz- Guzmán, Rosa María Cervantes-Tovar, Enrique Alcalá-Martínez, María Isabel Sandoval-Arrieta and Luz Arcelia Campos-Navarro

Infectology Hospital, National Medical Center "La Raza", Instituto Mexicano del Seguro Social, México

\begin{abstract}
Background: Candida albicans is a commensal fungus of the mucosa in humans that may become an opportunistic pathogen causing recurrent infections in immunocompromised hosts. In individuals with HIVIAIDS, Histatin-5 levels are significantly reduced, causing oropharyngeal candidiasis to become a pathological process. Clinical and in vitro resistance to azoles is common whether by selection or acquisition of Candida-resistant strains. In 2008, the Clinical and Laboratory Standards Institute (CLSI) defined the cutoff point for active agents against the isolates of Candida species. The objective of this study was to determine the frequency of fungal isolates of C. albicans through VITEK II system and their susceptibility pattern in patients with HIVIAIDS and oropharyngeal candidiasis treated at the Hospital for Infectious Diseases in Mexico City.
\end{abstract}

Methods: From June 2011-December 2012, there were 96 patients with HIVIAIDS and oropharyngeal candidiasis who were included in the study. Oral and esophageal specimens were directly examined to identify fungal structures. Cultures and sensitivity testing were done with the Vitek II method. Descriptive statistics and bivariate analysis were carried out.

Results: Of 96 patients, 87 had C. albicans oral isolates identified and 73 esophageal isolates. Non-albicans Candida (NAC) was identified in three and ten patients (oral and esophageal) respectively, and Cryptococcus neoformans was isolated in both sites. Sensitivity of $C$. albicans to fluconazole was demonstrated in 87/90 strains.

Conclusions: The fungal pathogen isolated was $C$. albicans followed by $C$. glabrata and $C$. parapsilosis. $C$. albicans was identified through VITEK II in $90 \%$ of cases susceptible to fluconazole.

Keywords: Fluconazole; Candida spp.; Vitek II; Oropharyngeal; AIDS

\section{Introduction}

The genus Candida comprises a large and diverse group of cultured yeasts that are part of the human microbiota and colonize the mucosa of the intestinal tract. Candida acts as an opportunistic pathogen that causes recurrent infection sunder immunodeficiency conditions. The oral cavity is the most common site of infection by C. albicans. It has been proposed that a potent salivary peptide with anti-Candida properties, Histatin-5, plays an important role in protecting against exposure of the oral mucosa to colonization by commensal strains of $C$. albicans. In individuals with HIV/AIDS, Histatin-5 levels are significantly decreased. Thus, oropharyngeal candidiasis is a pathological process directly related to ineffective immune response [1-4].

Variability in the pathogenic potential of this species of fungus is the result of its ability to adapt, evolve and invade the host immune defense through regulation of the factors determinant for virulence in a selective manner under predisposing conditions [5-8]. Among other pathogenic characteristics of $C$. albicans are the secretion of aspartic proteases and hydrolytic enzymes [2,3] as well as the phenotypic change, characterized by formation of hyphae or pseudo hyphae and with it the antigenic modulation that facilitates tissue invasion. These virulence factors may vary depending on type, stage and location of the infection and the nature of the immune response.

Other species of the Candida genus have been identified in esophageal an doral lesions including C. tropical, C. krusei, C. glabrata, C. parapsilosis, C. guilliermondii, and others [9-15]. Some species of this yeast are known to be intrinsically resistant to antifungal agents, i.e., $C$. krusei to fluconazole [5,16].
C. albicans readily develops resistance to fluconazole and may occur by the alteration in the sterol 14-alpha demethylase encoded by the ERG16 [17], drug inactivity and the presence of genes associated with the efflux pump such as the BENr, the Erg11 gene as well as the over expression of the genes Cdr1, Cdr2 and Mdr1 [18-20]. The adhesion to the cellular surface $[21,22]$ forming a biofilm [23] confer different levels of resistance to fluconazole as well as cross-resistance.

Since 2008, the Clinical and Laboratory Standards Institute (CLSI) defined the epidemiologic cut off point (ECVs) for active agents against isolates of Candida sp. The minimum inhibitory concentration (MIC) $<8 \mathrm{mg} / \mathrm{ml}$ established sensitivity (S),16-32 $\mu \mathrm{g} / \mathrm{ml}$ established the sensitive dose-dependent sensitivity (D-DS) and $>64 \mu \mathrm{g} / \mathrm{ml}$ was established as resistant [24-26], CLSI also established (ECVs) to evaluate the emergence of strains with reduced susceptibility to antifungal agents and served as a bridge for the establishment of species-specific susceptibility or clinical breakpoints (CBPs). In the case of CBPs for fluconazole, species-specific values were provided for C. albicans, $C$. tropicalis and C. parapsilosis. CLSI and EUCAST selected $\mathrm{S} \leq 2 \mathrm{mg} / \mathrm{mL}$, SDD4 $\mu \mathrm{g} / \mathrm{mL}$, and $\mathrm{R} \geq 8 \mu \mathrm{g} / \mathrm{mL}$ [27].

*Corresponding author: Veronica A. Gaona Flores, Hospital de Infectología, Centro Médico Nacional La Raza, Instituto Mexicano del Seguro Social, México, DF, México, Tel: 555-633-7337; E-mail: vgaona2@yahoo.com.mx

Received July 03, 2013; Accepted July 29, 2013; Published August 02, 2013

Citation: Gaona-Flores V, Guzmán RQ, Tovar RMC, Martínez EA, Arrieta MIS, et al. (2013) In vitro Sensitivity to Fluconazole through Vitek II Systems, of Strains of Candida spp. In Patients with Oropharyngeal Candidiasis and HIVIAIDS. J AIDS Clin Res 4: 230. doi:10.4172/2155-6113.1000230

Copyright: ( 2013 Gaona-Flores V, et al. This is an open-access article distributed under the terms of the Creative Commons Attribution License, which permits unrestricted use, distribution, and reproduction in any medium, provided the original author and source are credited. 
Page 2 of 5

Recurrent infection promotes resistance to antifungal and drug interaction. Reduced serum azole promotes poor clinical response to established treatment and resistance. There are various antifungals for treatment; however, it is important to prioritize treatment based on local epidemiology, which the clinician must determine for an appropriate therapeutic selection and thereby reduce the problem of resistance to azoles in species identification and sensitivity. The objective of this study was through to VITEK II system to determine the frequency of fungal isolates of C.albicans and their susceptibility pattern in patients with HIV/AIDS and oropharyngeal candidias is treated at the Infectious Diseases Hospital in Mexico City.

\section{Patients and Methods}

We performed a prospective cross-sectional study. We included adult patients diagnosed with HIV/AIDS treated as outpatients or inpatients from June 2011-December 2012. Patients had clinical suspicion of oral candidiasis and/or oropharyngeal candidiasis due to symptoms compatible with esophagitis and had upper endoscopy performed. All patients provided signed informed consent.

The study did not include patients with severe respiratory insufficiency $\left(\mathrm{pO}_{2}<40 \mathrm{mmHg}\right.$ ), obstructive nasal pathology such as tumors in the nasal vestibule, nasal stenosis after surgery, massive hematemesis, thrombocytopenia $<50,000$ platelets, and prothrombin time $>5 \mathrm{sec}$ with respect to control. We defined oral oresophageal candidiasis as the presence of erythematous white plaque lesions, inflammation or bleeding present in the oropharyngeal cavity. Fresh examination of these lesions with the presence of yeast and pseudomycelia and growth of colonies was suggestive of Candida $s p$ in Sabourad and Chromogenic chromID Candida (bioMerieux).

Identification and susceptibility were performed using the Vytek II v.05.06 system with YST card (MIC update to May 28, 2011 by CLSI criteria with reference strains): C. albicans ATCC 10231, C. parapsilosis ATCC22019, C. krusei ATCC6258, and C. glabrata ATCCMYA2950.

\section{Statistical analysis}

For descriptive analysis, we used simple frequencies, proportions, and measures of central tendency and dispersion.

Bivariate analysis: We calculated prevalence odds ratios with $95 \%$ confidence intervals and $\chi^{2}$ tests of association $(p<0.05)$. After analysis of the population distribution, we applied the Mann-Whitney U test for non-normally distributed variables and student $t$ test for normally distributed variables.

\section{Ethical aspects}

The study was submitted to the Local Committee on Health Research of the IMSS. All patients' signed informed consent for providing oropharyngeal specimens.

\section{Results}

We identified a male/female ratio of $6: 1$. The youngest patient was 17 years and the oldest patient were 63 years. Average age was 35 years with a standard deviation (SD) of 9.2 years. CD4+ lymphocyte counts were in the range of 9-82 cells $/ \mathrm{mm}^{3}$ (mean 29 CD4 cells \pm SD14.07).

Of the total patients, $>90 \%$ had $<1$ months in diagnosis of HIV according to clinical condition and CD4+ and were in AIDS stage (Table 1). There was a higher frequency of patients with no apparent added symptoms. Six patients were co-infected with hepatitis B virus and hepatitis $C$ virus (four and two cases, respectively). There was one case of histopathologically confirmed malignancy.

\begin{tabular}{|c|c|c|c|c|}
\hline & Minimum & Maximum & Mean & SD \\
\hline Age (years) & 17 & 63 & 35.26 & 9.2 \\
\hline CD4+ & 9 & 82 & 29.26 & 14.07 \\
\hline \multicolumn{3}{|l|}{ Gender } & No. & $\%$ \\
\hline \multicolumn{3}{|l|}{ Female } & 9 & 9.4 \\
\hline \multicolumn{3}{|l|}{ Male } & 87 & 90.6 \\
\hline \multicolumn{5}{|c|}{ Time since HIV diagnosis } \\
\hline \multicolumn{3}{|l|}{$<1$ month } & 90 & 93.8 \\
\hline \multicolumn{3}{|l|}{ 1-6 months } & 1 & 1.0 \\
\hline \multicolumn{3}{|c|}{6 months-1 year } & 5 & 5.2 \\
\hline \multicolumn{5}{|c|}{ Antimicrobial use prior to taking specimens for diagnosis of candidiasis } \\
\hline \multicolumn{3}{|l|}{ Yes } & 5 & 5.2 \\
\hline \multicolumn{3}{|l|}{ No } & 91 & 94.8 \\
\hline \multicolumn{5}{|c|}{ ARV treatment } \\
\hline \multicolumn{3}{|l|}{ Without ARV } & 96 & 100 \\
\hline \multicolumn{3}{|l|}{ With ARV } & 0 & 0 \\
\hline \multicolumn{5}{|c|}{ HIVIAIDS and comorbidity } \\
\hline \multicolumn{3}{|c|}{ Without apparent associated pathology } & 75 & 78.1 \\
\hline \multicolumn{3}{|c|}{ Viral hepatitis B-C } & 6 & 6.3 \\
\hline \multicolumn{3}{|l|}{ Latent syphilis } & 2 & 2.1 \\
\hline \multicolumn{3}{|c|}{ Pulmonary pneumocystis } & 4 & 4.2 \\
\hline \multicolumn{3}{|c|}{ Disseminated tuberculosis } & 3 & 3.1 \\
\hline \multicolumn{3}{|c|}{ Hodgkin's neoplasm } & 5 & 5.2 \\
\hline \multicolumn{3}{|c|}{ Encephalitis due to Toxoplasma gondii } & 1 & 1 \\
\hline
\end{tabular}

Table 1: Characteristics of the patients with HIVIAIDS and oropharyngeal candidiasis.

\begin{tabular}{|l|c|c|c|c|c|c|}
\hline \multirow{2}{*}{$\begin{array}{l}\text { Mouth } \\
(\boldsymbol{n}=\mathbf{9 6})\end{array}$} & \multicolumn{2}{|c|}{ Sensitive } & \multicolumn{2}{|c|}{$\begin{array}{l}\text { Intermediate } \\
(\mathbf{D}-\mathbf{R S})^{* *}\end{array}$} & \multicolumn{2}{|c|}{ Resistant } \\
\hline $\begin{array}{l}\text { No development } \\
\text { 5/96 (5.20\%) }\end{array}$ & No. & $\%$ & No. & $\%$ & No. & $\%$ \\
\hline C. albicans & - & - & - & - & - & - \\
\hline 90/96 (77\%) & 87 & 96.60 & 3 & 3.30 & 0 & 0.00 \\
\hline C. glabrata & 0 & 0.00 & 2 & 100.00 & 0 & 0.00 \\
\hline 2/96 (2.1\%) & 0 & 0.00 & 1 & 100.00 & 0 & 0.00 \\
\hline C. parapsilosis & & & & & \\
\hline 1/96 (1.07\%) & & & & & \\
\hline
\end{tabular}

Esophagus ( $n=83$ )

\begin{tabular}{|l|c|c|c|c|c|c|}
\hline $\begin{array}{l}\text { No development/no samples 14/96 } \\
\text { (14.58\%) }\end{array}$ & 0 & 0.00 & 0 & 0.00 & 0 & 0.00 \\
\hline C. albicans & 69 & 94.50 & 4 & 5.47 & 0 & 0.00 \\
\hline $73 / 96(87.95 \%)$ & 2 & 33.33 & 4 & 66.66 & 0 & 0.00 \\
\hline C. glabrata & 1 & 25 & 3 & 75 & 0 & 0.00 \\
\hline \begin{tabular}{l} 
6/96 (7.22\%) \\
\hline C. parapsilosis
\end{tabular} & 1 & &
\end{tabular}

Table 2: Susceptibility to fluconazole of the isolated strains from the mouth and esophagus.

Only 5/96 (5.2\%) patients received some type of antimicrobial; $1 / 5$ received fluconazole as primary prophylaxis, $1 / 5$ ceftriaxone, 2/5 antituberculosis treatment and 1/5 clindamycin + pyrimethamine. None of the patients had begun antiretroviral therapy (Table 1).

With regard to the endoscopic findings, the presence of minimal lesions predominated. In 4/96 (4.2\%) patients, stage IV of the Kodsi classification was identified, interpreted as abundant lesions and with light esophageal mucosa bleeding (Table 2). The most frequent oral clinical form was pseudo membranous candidiasis (93.7\%). Only in 
a few cases $(6.3 \%)$ was the mixed form (atrophic or erythematous) identified.

Of the specimens taken on directexamination, we observedincreased frequency of budding yeast and the presence of pseudomycelia. In other cases, we observed only yeast and, less frequently, blastoconidia. In the fungal isolates of oropharyngeal origin, C. albicans was more frequent. Of the genus non-albicans Candida (NAC), only two species were isolated: C. glabrata and C. parapsilosis. Identified yeast was Cryptococcus neoformans with oropharyngeal location. This patient underwent the study protocol and the organism was not identified elsewhere. The patient received antifungal treatment.

Susceptibility of C. albicans to fluconazole was $\sim 90 \%$. Isolates of NAC showed intermediate or dose-response sensitivity. No isolate was reported as resistant. Two different species were isolated from one patient: one from the mouth and the other from the esophagus. One case had intermediate sensitivity and the other one was sensitive.

There were $87 / 90$ oral isolates of C. albicans with fluconazole sensitivity, and 3/90 had intermediate sensitivity. Of those patients, one had fluconazole prophylaxis and two patients had two Candida strains and different species: C. albicans + C. glabrata and C. albicans with C. parapsilosis. With regard to the NAC isolates, three were identified with intermediate resistance or dose-response susceptibility. In five cases, there was no development, probably related with the size of the inoculums and taking of the specimen (Table 2).

In the esophagus, $69 / 73$ isolates of $C$. albicans were sensitive to fluconazole and $<6 \%$ had intermediate sensitivity. It should be noted that 2/6 strains of C. glabrata showed sensitivity to fluconazole. It has been reported that the species has shown intrinsic in vitro resistance and acquired a high in vivo percentage. In the case of C. parapsilosis, 3/4 isolates expressed intermediate or dose-response sensitivity.

In patients with CD4+ lymphocytes between 51 and 100 cells $/ \mathrm{mm}^{3}$ there was a 6-fold increase for risk of developing this disease without identifying statistical power. If the time of diagnosis of HIV infection is $>1$ month and antiretroviral treatment has not been administered, the risk increased six times for developing oral candidiasis ( $95 \% \mathrm{CI}, p>0.05$, non-significant). In patients $>50$ years of age, this was a risk factor for the development of oral candidiasis, with 1.5 times more risk than other groups ( $95 \% \mathrm{CI}, p=0.57$ non-significant) (Table 3).

Regarding esophageal candidiasis, bivariate analysis showed that diagnosis of HIV infection for $>1$ month increased the risk of developing esophageal candidiasis 1.5 times (95\% CI 0.26-9.02, $p>0.05$ ). Age range of 30-39 years was identified as an increased risk factor (1.6 times) for the development of esophageal candidiasis $v s$. other age groups in this sample.

\section{Discussion}

In the group of HIV-immunocompromised patients, decreased cellular type immunity favors the presence of infections considered as opportunistic, among them oral infections due to Candida sp. In this study, we found that the MIC of fluconazole for Candida sp. and reported sensitivity was $\leq 1 \mu \mathrm{g} / \mathrm{ml}$. For intermediate or dose-dependent sensitivity (D-DS), it was $44-32 \mu \mathrm{g} / \mathrm{ml}$ and $\geq 64 \mu \mathrm{g} / \mathrm{ml}$ as resistant according to the VYTEK II system and AST-YS01 cards with CLSI v.2011 criteria. Other species were not identified, probably due to the size of the sample.

We know that the constant and necessary use of antifungal agents in primary or secondary prophylaxis and treatment of oropharyngeal

\begin{tabular}{|c|c|c|c|c|}
\hline \multicolumn{5}{|l|}{ Oral candidiasis } \\
\hline Variable & POR & $95 \% \mathrm{Cl}$ & $\chi^{2}$ & $p$ \\
\hline \multicolumn{5}{|l|}{ Gender } \\
\hline Female & 1 & - & - & - \\
\hline Male & 0.3 & $0.05-1.76$ & 1.92 & 0.19 \\
\hline \multicolumn{5}{|c|}{ Use of antimicrobials } \\
\hline Yes & 1 & - & - & - \\
\hline No & 1.11 & 1.03-1.18 & 0.54 & 0.6 \\
\hline \multicolumn{5}{|l|}{ Susceptibility } \\
\hline Intermediate & 1 & - & - & - \\
\hline Sensitive & 0.14 & $0.02-0.74$ & 6.7 & 0.03 \\
\hline \multicolumn{5}{|c|}{ CD4 lymphocytes } \\
\hline$<50$ & 1 & - & - & - \\
\hline $51-100$ & 5.9 & $0.91-38.25$ & 4.32 & 0.09 \\
\hline \multicolumn{5}{|c|}{ Time since HIV diagnosis } \\
\hline$<1$ month & 1 & - & - & - \\
\hline$>1$ month & 5.92 & $0.91-38.25$ & 4.32 & 0.09 \\
\hline \multicolumn{5}{|c|}{ Age group (years) } \\
\hline $17-29$ & 1 & - & - & - \\
\hline 30-39 & 1.12 & $0.19-6.60$ & 0.89 & 0.63 \\
\hline $40-49$ & 1.43 & $0.18-11.2$ & 0.72 & 0.56 \\
\hline$\geq 50$ & 1.64 & $0.12-20.9$ & 0.7 & 0.57 \\
\hline \multicolumn{5}{|c|}{ Esophageal candidiasis } \\
\hline \multicolumn{5}{|l|}{ Gender } \\
\hline Female & 1 & - & - & - \\
\hline Male & 1.18 & $0.22-6.1$ & 0.04 & 0.6 \\
\hline \multicolumn{5}{|c|}{ Use of antimicrobials } \\
\hline Yes & 1 & - & - & - \\
\hline No & 1.35 & $0.14-12.7$ & 0.7 & 0.63 \\
\hline \multicolumn{5}{|l|}{ Susceptibility } \\
\hline Intermediate & 1 & - & - & - \\
\hline Sensitive & 0.06 & $0.01-0.36$ & 14.7 & 0.001 \\
\hline \multicolumn{5}{|c|}{ CD4 lymphocytes } \\
\hline$<50$ & 1 & - & - & - \\
\hline $51-100$ & 0.73 & $0.64-0.83$ & 2.13 & 0.16 \\
\hline \multicolumn{5}{|c|}{ Time since HIV diagnosis } \\
\hline$<1$ month & 1 & - & - & - \\
\hline$>1$ month & 1.54 & $0.26-9.02$ & 0.23 & 0.46 \\
\hline \multicolumn{5}{|c|}{ Age groups (years) } \\
\hline $17-29$ & 1 & - & - & - \\
\hline $30-39$ & 1.62 & $0.50-5.25$ & 0.41 & 0.3 \\
\hline $40-49$ & 1.14 & $0.25-5.02$ & 0.85 & 0.57 \\
\hline$\geq 50$ & 1.33 & $0.20-8.70$ & 0.76 & 0.55 \\
\hline POR, prevalence & & & & \\
\hline
\end{tabular}

Table 3: Bivariate analysis of the risk factors for oral and esophageal candidiasis.

candidiasis in AIDS patients favors the selection of resistant strains and contributes to the change in the spectrum of Candida nonalbicans species. Under these circumstances, this study determined the frequency of the identification of Candida albicans and in vitro susceptibility through Vitek II system, since it is an automated resource more accessible than micro dilution techniques.

With the standardization of antifungal susceptibility, procedures such as those established by the Clinical and Laboratory Standards 
Institute (CLSI) and European Committee on Antimicrobial Susceptibility Testing (EUCAST), the need for automated commercial systems has been created, which has been considered as a way to optimize time and resources without neglecting the quality required. In the case of the Vitek system II, antifungal susceptibility is determined by spectrophotometry to identify the genus and species for determination of the MIC. This system was approved by U.S. FDA in 2006 for clinical use and to detect resistance to fluconazole $[28,29]$.

The cutoff point for susceptibility was established by the CLSI as well as by EUCAST, both for fluconazole as well as for voriconazole vs. Candida. The CLSI suggested using values of $\leq 8 \mu \mathrm{g} / \mathrm{mL}$ as susceptible (S), $16-32 \mathrm{mg} / \mathrm{mL}$ as DDS, and $\geq 64 \mathrm{mg} / \mathrm{mL}$ as resistant (R) for all species.

We consider that when encountering epidemilogic cutoff point (ECVs), (24-26) allows us to assess the emergence of strains with established resistant. ECVs have also served as a bridge to establish specific species susceptibility and clinical breakpoints (CBPs), which in the case of fluconazole were determined for C. albicans, C. tropicalis and C. parapsilosis. CLSI and EUCAST selected S $\leq 2 \mathrm{mg} / \mathrm{mL}$, SDD $4 \mu \mathrm{g} /$ $\mathrm{mL}$ and $\mathrm{R} \geq 8 \mu \mathrm{g} / \mathrm{mL}$.

Fluconazole is the first-line antifungal drug in the treatment of oral and/or esophageal candidiasis [30,31]. The intervention of other species of non-albicans Candida in immune compromised hosts and the increased availability of new antifungal agents as well as frequent reports of resistance to C. albicans associated with therapeutic failures makes it imperative to have antifungal susceptibility testing in routine microbiology laboratories, a situation that guides clinicians.

The results of this study are from a single center performed with a VITEK II, incorporated into the proposal to continue the surveillance of antifungal susceptibility of Candida albicans and other species. In this paper, we describe fungal isolates of different species in the oral cavity and esophagus.

With regard to Candida glabrata isolates, we found that susceptibility was dose dependent (DDS) according to the findings by CLSI that chose to place the CBPs for fluconazole and C. glabrata $\leq 32$ $\mu \mathrm{g} / \mathrm{mL}$ for SDD and $\geq 64 \mu \mathrm{g} / \mathrm{mL}$ for $\mathrm{R}$.

Factors that affect the clinical response are as follows: immunological status of the patient [32], treatment adherence and presence of a biofilm due to Candida sp. [33] as well as frequent drug interactions.

As for the resistance to antifungal agents used by the Vytek II system, none of the Candida sp. strains isolated was found to be resistant, although they were found with intermediate resistance. The explanation for this phenomenon is unclear, considering that the main risk factor is prolonged prior exposure to azoles, a circumstance not experienced by any of the patients.

Although candidiasis of the oropharyngeal mucosa is common in immunecompromised patients due to HIV/AIDS, chronic diseases with immunosuppression such as those of hematological, oncological, and metabolic origin along with the parallel increase of high-risk patients with neoplasms and transplants, low birth weight newborns, elderly patients or patients who have had extensive surgery performed and were hospitalized in the ICU, use of intravascular catheters and diagnostic therapeutic procedures or invasive support have coincided with a marked increase of invasive mycosis. Infections in these groups of patients also require identification of the genus and species of the fungus.
The choice of an antifungal agent should take into account several factors including previous exposure to antifungal agents and correct identification of the species.

\section{Conclusions}

There have been reports of resistance to fluconazole in C. albicans, which is the most frequent etiologic agent isolated in oropharyngeal candidiasis in patients immune compromised due to HIV/AIDS. We should consider that the occurrence of antimicrobial resistance is related to exposure to antimicrobial agents, dose, and target site and treatment adherence without neglecting drug interactions that may occur in each case. This study did not identify acquired resistance of $C$. albicans to fluconazole.

There is a need for automated commercial systems so as to optimize time and resources without neglecting the quality involved in detecting resistance to fluconazole. Vitek II was approved by the U.S. FDA. There are several publications that said that Vitek II system is highly reproducible with excellent categorical agreement with the CLSI microdilution reference procedure ( $>95 \%$ ) for fluconazole, this system was able to determine the MIC endpoint after 9.1 to $27.1 \mathrm{~h}$ of incubation (mean 12 to $14 \mathrm{~h}$ ) the U. S. FDA approved in 2006 the clinical use of this system [28]

We found intermediate resistance to fluconazole in C. glabrata. All this confirms that we should always report susceptibility to antifungal agents. In the case of these types of species, we are aware of their intrinsic and acquired resilience and we should rule out the presence of non-albicans Candida in order to provide the best antifungal treatment to the patient. When added to the immune status, decreased drug interaction and treatment adherence would contribute to controlling the fungal infection process.

Regarding the $\mathrm{p}$ values greater than 0.05 , they are correlated with confidence intervals, in this case they pass through the unit, these circumstances statistics are related to the size of the sample, which was small. Some data show increased risk, which would be clearer with increasing the sample size because the values of $p$, as the confidence intervals are directly influenced by the population studied [34].

\section{Funding}

No external funding source was received for this study.

\section{References}

1. Ceballos Salobreña A, Gaitán Cepeda LA, Ruesga MT, Ceballos García L, Quindós G (1998) [Prevalence of oral lesions by Candida sp.: Their varieties and serotypes in a population of patients with AIDS under a highly active antiretroviral therapy.]. Rev Iberoam Micol 15: 141-145.

2. Meiller TF, Hube B, Schild L, Shirtliff ME, Scheper MA, et al. (2009) A novel immune evasion strategy of candida albicans: proteolytic cleavage of a salivary antimicrobial peptide. PLoS One 4: e5039.

3. de Repentigny L, Lewandowski D, Jolicoeur P (2004) Immunopathogenesis of oropharyngeal candidiasis in human immunodeficiency virus infection. Clin Microbiol Rev 17: 729-759, table of contents.

4. Puerto JL, García Martos P, Márquez A, García Agudo L, Mira J (2001) Candidiasis orofaríngea. Rev Diagn Biol 50: 177-181.

5. Orozco AS, Higginbotham LM, Hitchcock CA, Parkinson T, Falconer D, et al (1998) Mechanism of fluconazole resistance in Candida krusei. Antimicrob Agents Chemother 42: 2645-2649.

6. Sánchez-Vargas LO, Ortiz-López NG, Villar M, Moragues MD, Aguirre JM, et al. (2005) Point prevalence, microbiology and antifungal susceptibility patterns of oral Candida isolates colonizing or infecting Mexican HIVIAIDS patients and healthy persons. Rev Iberoam Micol 22: 83-92.

7. Lattif AA, Banerjee U, Prasad R, Biswas A, Wig N, et al. (2004) Susceptibility 
Citation: Gaona-Flores V, Guzmán RQ, Tovar RMC, Martínez EA, Arrieta MIS, et al. (2013) In vitro Sensitivity to Fluconazole through Vitek II Systems, of Strains of Candida spp. In Patients with Oropharyngeal Candidiasis and HIVIAIDS. J AIDS Clin Res 4: 230. doi:10.4172/2155-6113.1000230

pattern and molecular type of species-specific Candida in oropharyngeal lesions of Indian human immunodeficiency virus-positive patients. J Clin Microbiol 42: 1260-1262.

8. Mujica MT, Finquelievich JL, Jewtuchowicz V, lovannitti CA (2004) [Prevalence of Candida albicans and Candida non-albicans in clinical samples during 19992001]. Rev Argent Microbiol 36: 107-112.

9. Enwuru CA, Ogunledun A, Idika N, Enwuru NV, Ogbonna F, et al. (2008) Fluconazole resistant opportunistic oro-pharyngeal Candida and non-Candida yeast-like isolates from HIV infected patients attending ARV clinics in Lagos, Nigeria. Afr Health Sci 8: 142-148.

10. Sanglard D, Bille $J(2002)$ Current understanding of the modes of action of and resistance mechanisms to conventional and emerging antifungal agents for treatment of Candida infections. In Calderone RA (Ed.), Candida and Candidiasis. ASM Press, Washington, DC, 349-383.

11. Pappas PG (2006) Invasive candidiasis. Infect Dis Clin North Am 20: 485-506.

12. Perlroth J, Choi B, Spellberg B (2007) Nosocomial fungal infections: epidemiology, diagnosis, and treatment. Med Mycol 45: 321-346.

13. Kollef MH, Napolitano LM, Solomkin JS, Wunderink RG, Bae IG, et al. (2008) Health care-associated infection (HAI): a critical appraisal of the emerging threat-proceedings of the HAI Summit. Clin Infect Dis 47 Suppl 2: S55-99.

14. Quindós G (2010) [Nosocomial candidemias and invasive candidiasis]. Med Clin (Barc) 134: 17-19.

15. Gabler IG, Barbosa AC, Velela RR, Lyon S, Rosa CA (2008) Incidence and anatomic localization of oral candidiasis in patients with AIDS hospitalized in a public hospital in Belo Horizonte, MG, Brazil. J Appl Oral Sci 16: 247-250.

16. St-Germain G, Laverdière M, Pelletier R, Bourgault AM, Libman M, et al. (2001) Prevalence and antifungal susceptibility of 442 Candida isolates from Blood and other normally sterile sites: results of a 2-year (1996 to 1998) multicenter surveillance study in Quebec, Canada. J Clin Microbiol 39: 949-953.

17. Sampaio P, Gusmão L, Correia A, Alves C, Rodrigues AG, et al. (2005) New microsatellite multiplex PCR for Candida albicans strain typing reveals microevolutionary changes. J Clin Microbiol 43: 3869-3876.

18. Sanglard D, Kuchler K, Ischer F, Pagani JL, Monod M, et al. (1995) Mechanisms of resistance to azole antifungal agents in Candida albicans isolates from AIDS patients involve specific multidrug transporters. Antimicrob Agents Chemother 39: $2378-2386$

19. Ramage G, Bachmann S, Patterson TF, Wickes BL, López-Ribot JL (2002) Investigation of multidrug efflux pumps in relation to fluconazole resistance in Candida albicans biofilms. J Antimicrob Chemother 49: 973-980.

20. Perea S, Lopez-Ribot JL, Kirkpatrick WR, McAtee RK, Santillan RA, et al (2001) Prevalence of molecular mechanisms of resistance to azole antifungal agents in Candida albicans strains displaying high-level fluconazole resistance isolated from human immunodeficiency virus-infected patients. Antimicrob Agents Chemother 45: 2676-2684.

21. Sanglard D, Odds FC (2002) Resistance of Candida species to antifungal agents: molecular mechanisms and clinical consequences. Lancet Infect Dis 2: 73-85.
22. Fu Y, Luo G, Spellberg BJ, Edwards JE Jr, Ibrahim AS (2008) Gene overexpression/suppression analysis of candidate virulence factors of Candida albicans. Eukaryot Cell 7: 483-492.

23. Ramage G, Vande Walle K, Wickes BL, López-Ribot JL (2001) Biofilm formation by Candida dubliniensis. J Clin Microbiol 39: 3234-3240.

24. Rex JH, Pfaller MA, Galgiani JN, Bartlett MS, Espinel-Ingroff A, et al. (1997) Development of interpretative breakpoints for antifungal susceptibility testing: conceptual framework and analysis of In vitro - In vivo correlation date for fluconazole, itraconazole, and Candida infections. Clin Infect Dis 24: 235-247.

25. Pfaller MA, Boyken LB, Hollis RJ, Kroeger J, Messer SA, et al. (2008) Validation of 24-hour fluconazole MIC readings versus the CLSI 48-hour broth microdilution reference method: results from a global Candida antifungal surveillance program. J Clin Microbiol 46: 3585-3590.

26. Pfaller MA, Diekema DJ, Sheehan DJ (2006) Interpretive breakpoints fo fluconazole and Candida revisited: a blueprint for the future of antifungal susceptibility testing. Clin Microbiol Rev 19: 435-447.

27. Pfaller MA (2012) Antifungal drug resistance: mechanisms, epidemiology, and consequences for treatment. Am J Med 125: S3-13.

28. Pfaller MA, Diekema DJ, Procop GW, Rinaldi MG (2007) Multicenter comparison of the VITEK 2 antifungal susceptibility test with the CLSI broth microdilution reference method for testing amphotericin B, flucytosine, and voriconazole against Candida spp. J Clin Microbiol 45: 3522-3528.

29. Cuenca-Estrella M, Gomez-Lopez A, Alastruey-Izquierdo A, Bernal-Martínez L, Cuesta I, et al. (2010) Comparison of the Vitek 2 antifungal Susceptibility System with the Clinical and Laboratory Standards Institute (CLSI) and European Committee on Antimicrobial Susceptibility Testing (EUCAST) Broth Microdilution Reference Methods and with the Sensititre Yeast One and Etest Techniques for In Vitro Detection of Antifungal Resistance in Yeast Isolates. $J$ Clin Microbiol 48: 1782-1786.

30. Pappas PG, Kauffman CA, Andes D, Benjamin DK Jr, Calandra TF, et al. (2009) Clinical practice guidelines for the management of candidiasis: 2009 update by the Infectious Diseases Society of America. Clin Infect Dis 48: 503-535.

31. Kaplan JE, Benson C, Holmes KH, Brooks JT, Pau A, et al. (2009) Guidelines for prevention and treatment of opportunistic infections in HIV-infected adults and adolescents: recommendations from CDC, the National Institutes of Health, and the HIV Medicine Association of the Infectious Diseases Society of America. MMWR Recomm Rep 58: 1-207.

32. Farah CS, Elahi S, Drysdale K, Pang G, Gotjamanos T, et al. (2002) Primary role for $\mathrm{CD} 4(+) \mathrm{T}$ lymphocytes in recovery from oropharyngeal candidiasis. Infect Immun 70: 724-731.

33. Jabra-Rizk MA, Falkler WA, Meiller TF (2004) Fungal biofilms and drug resistance. Emerg Infect Dis 10: 14-19.

34. Manterola DC, Pineda NV, El valor de "p" y la (2008) significación estadística Aspectos generales y su valor en la práctica clínica. Interpretation of medica statistics. Rev Chilena de Cirugía 60: 86-89. 